\title{
ENERGY EFFICIENCY IN BUILDINGS IN SOUTHERN EUROPE: CHALLENGES AND DESIGN STRATEGIES
}

\author{
A. BOERI \& D. LONGO \\ University of Bologna, Department of Architecture and Territorial Planning - Faculty of Architecture \\ 'Aldo Rossi', Cesena - Italy.
}

\begin{abstract}
The increasing attention paid to energy efficiency in buildings by researches has led toward solutions favoring the adaptation of the European passive house standard, developed and codified mainly in cold contexts, to different climate contexts, in particular the Mediterranean one.

In warm areas, energy efficiency is related to summer performance and the passive cooling of buildings.

In southern and central Italy, the main factor is the heat control, which regards just the summer period during which situations of overheating occur - this implies significant energy consumption due to conditioning systems, therefore it has to be restricted. It may be possible that the energy required to cool buildings exceeds the requirements for heating. This implies that the criteria for energy efficiency projects should be revisited and adapted to specific national climatic situations, even by recovering and updating design criteria and techniques adopted in traditional building.

Relevant experiences are also developing in Italy, where the Mediterranean climate has different characteristics compared to the cold climates of central and northern Europe. An interesting project is presented as an indicative case study of experimentation in this field.
\end{abstract}

Keywords: energy efficiency, Mediterranean architecture, passive house, technology.

\section{INTRODUCTION}

The European codification of the passive building is the highest performance standard in the field of energy efficiency of buildings, since a passive house can take advantage of climatic factors to minimize its energy needs while ensuring indoor comfort conditions without the use of fossil fuels.

In May 2010, a recast (2010/31/EU) of The Directive on energy performance of buildings (2002/91/ EC) was adopted to strengthen the energy performance requirements. Buildings are responsible for $40 \%$ of the total energy consumption and $36 \%$ of $\mathrm{EU} \mathrm{CO}_{2}$ emissions (data of EU Commission, September 2011). Energy performance of buildings is the key for achieving the EU Climate \& Energy objectives, namely a reduction of $20 \%$ of the greenhouse gases emissions and a $20 \%$ energy savings by 2020 [1].

The EU needs to act now to get on track to achieve its target. Responding to the call of the European Council of 4 February 2011 to take 'determined action to tap the considerable potential for higher energy savings of buildings, transport and products and processes', the Commission has therefore developed this comprehensive new Energy Efficiency Plan.

According to the passive standards, buildings should consume no more than $15 \mathrm{kWh} / \mathrm{m}^{2}$ for heating, about one-tenth of the consumption of a traditional building, providing both optimum living conditions and healthy indoor microclimate, foregoing traditional heating systems, with much lower costs than standard buildings [2].

The subject, developed by the Passivhaus Institute in Darmstadt [3], has been thoroughly analyzed in researches and experimentations in Europe, such as, for instance, the Cepheus project - Cost Efficient Passive Houses as European Standards [4] - consisting of the implementation and monitoring of 250 housing units, testing the potential effects of alternative approaches, and to define solutions and technologies to erect low energy buildings on budget.

Other parameters that characterize a passive building are: the ratio between dispersant surface and heated volume, the total primary energy demand for all uses (heating, hot water, lighting, electrical, 
cooling) less than $120 \mathrm{kWh} / \mathrm{m}^{2}$, the absence of thermal bridges, the extremely low values of transmittance and high water resistance of the opaque and clear envelope, the presence of a mechanical ventilation system with a high efficiency heat recovery rate [5].

The passive house standard, developed mainly in the cold climates of Central and Northern Europe, is currently under revision to adapt its application to the warmer climates of the Mediterranean area, where the priority is summer air conditioning rather than winter heating [6]. So, an upper limit of power consumption of $15 \mathrm{kWh} / \mathrm{m}^{2}$ for summer cooling has been established to compensate the very same limit set for winter heating [7].

Italy is characterized by different climatic contexts, ranging from predominantly cold (Alpine) to hot (southern regions and islands), with intermediate areas where changes in temperature and humidity are related to the seasons alternation.

Compared to the recently encoded central European experiences, the Italian one is important for defining different design solutions for each different climatic context, aiming at reducing energy consumption both during winter and summer periods [8].

In these contexts, the envelope has to reduce transmittance and, at the same time, ensure the thermal inertia of its elements.

The concept of 'thermal inertia' is simple to define; however, this factor is difficult to calculate. Simply put, it can be defined as the combined effect of the capacity of accumulation and heat resistance of the structure, as shown in Fig. 1.

The coefficient of the phase displacement allows to evaluate the delay in the transmission of the external thermal gradient against the temperature changes inside the building.

To obtain sufficient comfort conditions, the lag should not be less than 8 hours, whereas optimal conditions are achieved in just 12 hours.

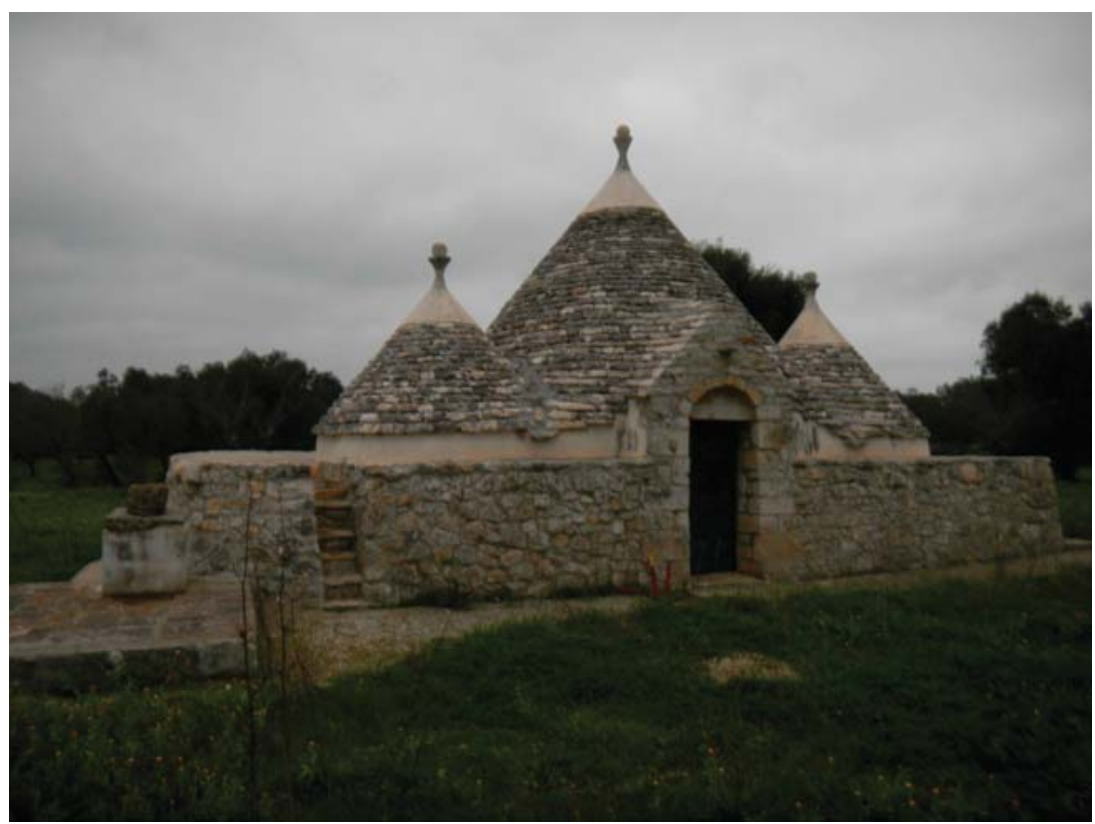

Figure 1: The massive envelope assures high performances in terms of thermal inertia in a warm climate context. 'Trullo', a traditional construction in Southern Italy, Puglia (HGT = 1100; monthly average outside temperature during the winter heating period of $10.7^{\circ} \mathrm{C}$ ). 


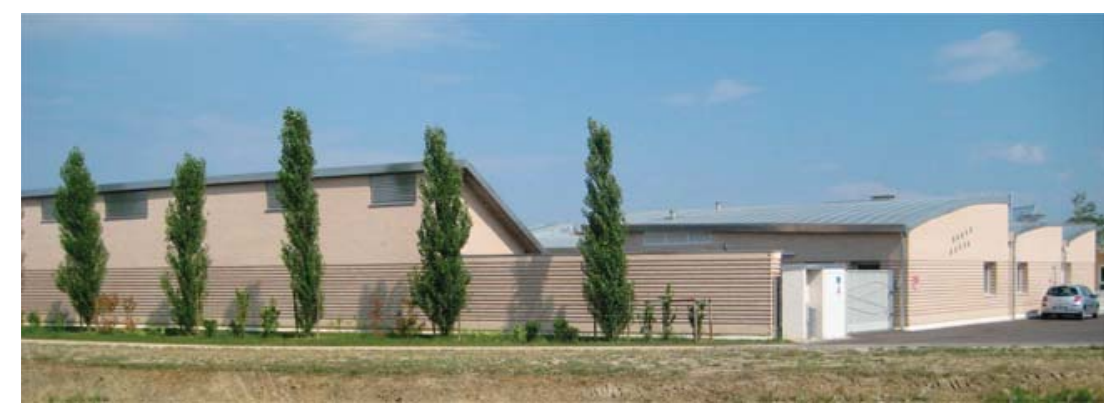

Figure 2: 'Lama Sud' school - Ravenna, Italy. Its massive envelope assures high performances also in warm climate context. HGT $=2,227$ and the monthly average outside temperature during the winter heating period of $6.62^{\circ} \mathrm{C}$, a climate characterized by cold winters and hot summers.

Therefore, in addition to the transmittance and particularly during summer, it is important to assess the contribution of the massive materials in relation to the higher heat capacity to reduce the effects of external thermal variations on the microclimate indoor.

Lots of traditional Italian architectures can represent simple but interesting bioclimatic reference models: they are able to maintain sufficiently constant temperature indoor, even without auxiliary fixtures and fittings, thanks to a correct architectural form and exposure, the relationship with the soil, and, in particular, to the thickness and mass of their envelope. Refer Fig. 2.

\section{THE ITALIAN CONTEXT}

The Italian climatic context is mainly Mediterranean, with significant differences from the predominantly cold north-central European one, where the most significant researches and experiences aimed at reducing energy consumption in constructions have been developed and carried out [8].

In countries, such as Germany, Austria, Switzerlsand, and Scandinavia, the research on energy efficiency and the concept of passive house are related mainly to cold contexts, characterized by cold winters during which the priority is the containment of heat loss; conditions of overheating are unusual during summer $[9,10]$.

First of all, the buildings must provide high levels of thermal insulation to contain energy losses during winter; their clear parts should allow entry to solar radiation to favor both lighting inside and passive heating without raising the transmittance of the thermal envelope.

In these contexts, problems related to overheating in summer or presence of moisture are less important. Lots of Italian regions have different climates, where, according to the season, protection from summer heat or a reduction of energy consumption for heating during winter is important. Buildings have to relate with different situations, cold winters and hot summers, always providing a suitable performance [11].

The climatic context plays an essential role in the design strategy to be adopted. The indicator of specific climatic conditions are the degrees days (HGT), these are proportional to the need for heating of buildings in specific locations.

According to D.P.R. n. 412 of 1993 (Italy), they are the sum, extended to every day of an annual period of conventional heating, of the only positive differences between the daily temperature, conventionally set at $20^{\circ} \mathrm{C}$, and the average outside daily temperature. And, according to this Presidential Decree, Italy is divided into six climatic zones, with regards to degree-days.

In Germany, the average of a degrees day is 3500, whereas six different climatic zones are identified in Italy by UNI 10379 (attached to the DPR No 412, 1993) where the warmer area (A) has less 
than 600 degrees day. For instance, Palermo is characterized by 751 degrees day, Naples 1034, Rome 1415, Florence 1821, Bologna 2259, Milan 2404, Turin 2617, Bolzano 2791 and Selva di Val Gardena 5072, as shown in Figs. 3 and 4.

This implies that the criteria for energy efficiency projects, developed and codified mainly in cold contexts, should be revisited and adapted to specific national climatic situations, even by recovering and updating design criteria and techniques adopted in traditional building.

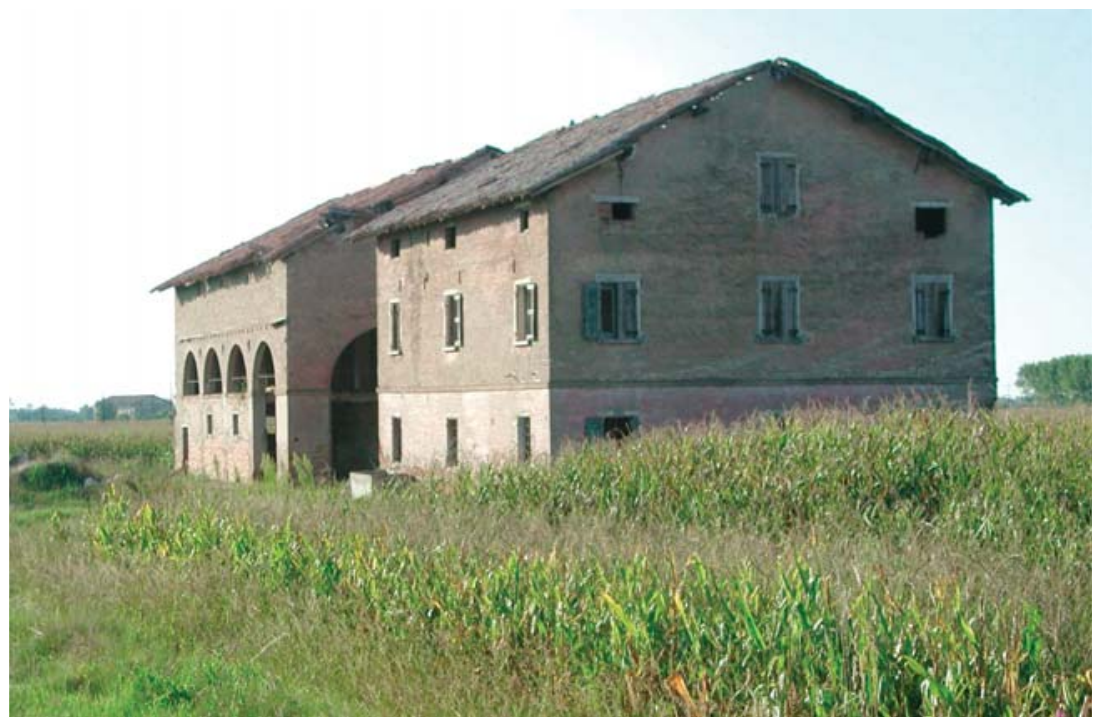

Figure 3: A traditional rural building in Italy, Emilia Romagna, HGT $=2560$, the monthly average outside temperature during the winter heating period is of $5.96^{\circ} \mathrm{C}$, characterized by massive materials and protection elements from solar radiation. The compact volume provides a favorable ratio $\mathrm{S} / \mathrm{V}=0.6$ (ratio between dispersant surfaces and heated volume).

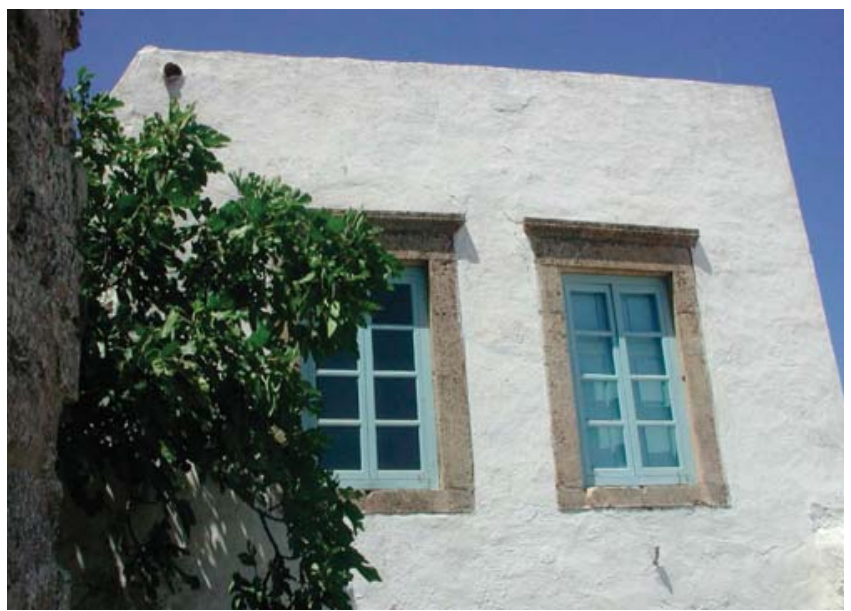

Figure 4: Typical Mediterranean building in Southern Italy. Palermo has HGT $=751$ and the monthly average outside temperature during the winter heating period is $12.11^{\circ} \mathrm{C}$. 


\section{THERMAL INSULATION}

A building construction should ensure high levels of thermal insulation to restrain heat dispersion during winter; its clear parts should allow entry to solar radiation, useful for indoor lighting and important for its contribution for passive heating of the interiors without raising the transmittance of the building shell.

It is necessary that the thermal layer of the envelope be continuous and characterized by low U-factor to ensure the efficiency of energy performance.

We can consider as a reference the high efficiency values of CasaClima: the standard for Class A ranges from 0.1 to $0.2 \mathrm{~W} / \mathrm{m}^{2} \mathrm{~K}$ for private homes and from 0.15 to $0.25 \mathrm{~W} / \mathrm{m}^{2} \mathrm{~K}$ for block buildings (values are higher when the volume factor is favorable). L.D. 311/06, amended the previous L.D. 192/05 implementing The Directive 2002/91/EC on energy efficiency in the construction sector, requires less restrictive values: depending on the climatic zones, the values change from $0.85 \mathrm{~W} / \mathrm{m}^{2} \mathrm{~K}$ (zone A until the end of 2007) to $0.33 \mathrm{~W} / \mathrm{m}^{2} \mathrm{~K}$ (area $\mathrm{F}$ from 2010). In general, the required values of transmittance decrease starting from the warmer climatic zones (A) to the coldest ones (F) [12].

Insulation is necessary to assure energy efficiency: a high mass contributing to increase the thermal inertia of the system is not sufficient to limit the thermal conductivity of the building envelope.

For instance, for a natural stone wall $60 \mathrm{~cm}$ thick, plastered on its sides, we can assume a value of thermal transmittance of $2,20 \mathrm{~W} / \mathrm{m}^{2} \mathrm{~K}$, about seven times higher than what would be necessary to benefit in terms of a discrete containment of energy. To limit heat transmission, the application of appropriate layers of insulating material is necessary: in general, monolayer constructive solutions do not provide sufficient insulation in cold climates, even when using efficient elements of brick.

Light-technologies and insulated solutions for building envelopes have good performances in terms of thermal transmittance, widely applied in cold climates, mostly realized with wooden frames and gaps filled with insulating material, thermal layers, and protective coverings. With these solutions you can get very interesting and low values, of about $0.20 \mathrm{~W} / \mathrm{m}^{2} \mathrm{~K}$, due to a gap filled with bulk insulation, such as mineral wool, to the low thermal conductivity of wood, used as frame (conifer wood has a thermal conductivity coefficient - in the transverse fibers - of $\lambda=0.13 \mathrm{~W} / \mathrm{mK}$ ), further protected by a layer of external insulation, as shown in Fig. 5.

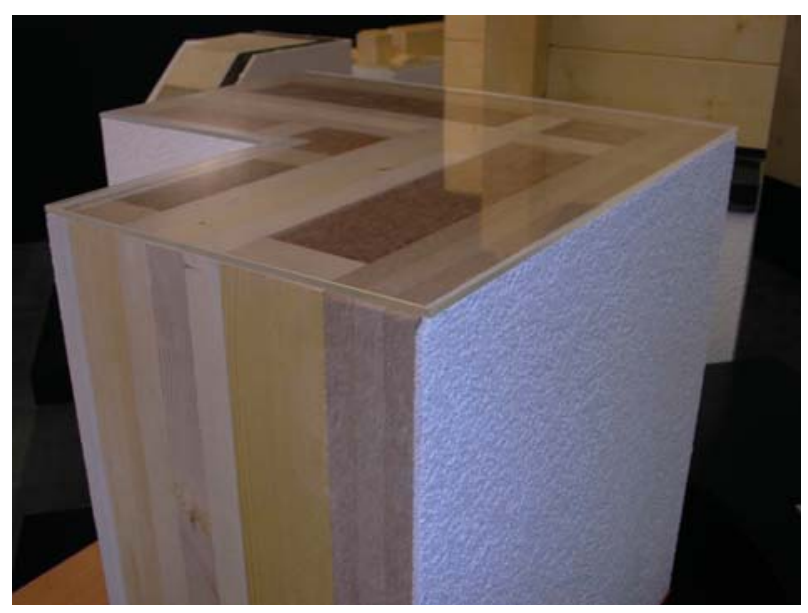

Figure 5: Thermal insulated solutions for efficient envelopes with wooden structure, $U<0.2 \mathrm{~W} / \mathrm{m}^{2} \mathrm{~K}$. 


\section{THERMAL INERTIA}

Since recent researches have been primarily aimed at codifying appropriate construction technologies for the containment of energy during winter, it seems appropriate to focus on the climatic characteristics, in particular on the passive protection from summer heat.

To increase the heat capacity of building technological layers, you can use insulation with a higher thermal mass, such as panels of wood fiber (with a density ranging from 130 to $190 \mathrm{~kg} / \mathrm{m}^{3}$ ), with very good hygroscopic performances. In general, lightweight solutions have no considerable heat capacity, that is, they don't sufficiently contribute in delaying the transmission of the external thermal variations.

If heat insulation is the most important factor, and the most codified one from a regulatory point of view, as regards different climates, in particular warm ones, the role of thermal inertia of a building system gradually assumes importance. Traditional Italian architectures, such as the Apulia 'trulli' [13] and 'dammusi' of Pantelleria, can represent simple but effective bioclimatic reference models: they are able to maintain sufficiently constant indoor temperature, even without the aid of auxiliary fixtures and fittings, thanks to a correct architectural form, their exposure, the relationship with the soil, and in particular, to the thickness and mass of their envelope.

The coefficient of phase displacement allows to evaluate the delay in transmission of the external thermal gradient changes to the interior [14]. To obtain sufficient comfort conditions, lag should not be less than 8 hours, whereas optimal conditions are achieved in just 12 hours.

Therefore, especially during summer and in addition to the transmittance, it is important to assess the contribution of the massive materials, in relation with the higher heat capacity to reduce the effects of external thermal variations on the microclimate indoor, as shown in Fig. 6.

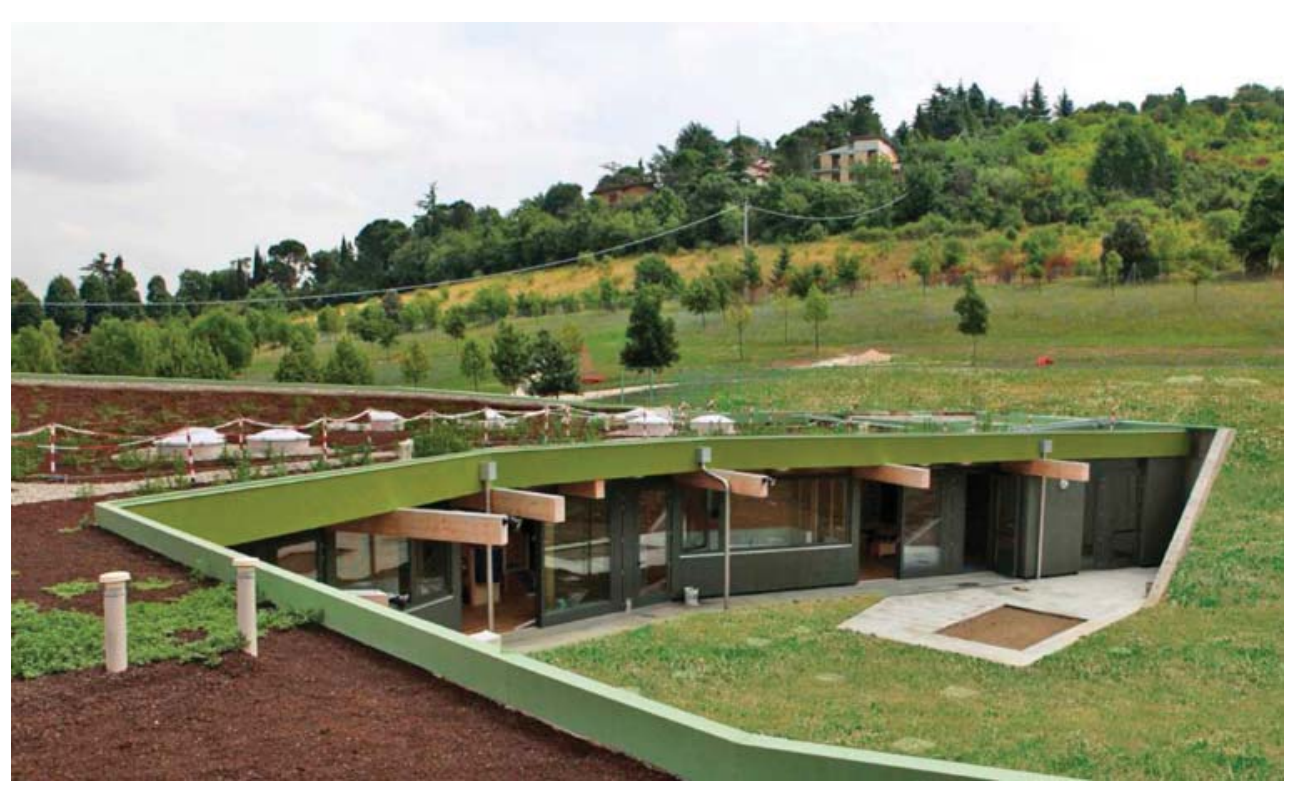

Figure 6: A green roof can contribute toward the increase of thermal inertia. A green roof is an element of integration with the environment and of microclimatic control. It has a thermal transmittance $\mathrm{U}=0.20 \mathrm{~W} / \mathrm{m}^{2} \mathrm{~K}$ and a phase displacement of 10 hours. Day nursery, Gainaido in Bologna (HGT = 2259), 2009 Tasca Studio. 
The evaluation systems related to thermal transmittance, disregarding the role of the mass, refer to calculation methods concerning theoretical hypothesis of stationary heat transfer systems, allowing more simplified operation. To the contrary, to evaluate properly the role of thermal inertia, and then analyze the performance of a building even during summer, it is necessary to refer to the dynamic state analysis that require more complex calculation methods, which presumes necessary high abilities.

\section{DESIGN STRATEGIES}

The role of heat inertia, although extremely important in the characterization of energy efficiency of buildings during summer, cannot leave aside a more general design strategy aimed at a correct relationship with the environment.

Among the main parameters, the most important ones are the location, shape, and orientation of the building: a southern orientation and shade considerations (as shown in Fig. 7) are some of the basic features that characterize passive house construction [15].The ratio of dispersing surfaces and volume is an index of energy efficiency and it is considered a reference for regulations.

Other features of a passive house consist of a suitable distribution of rooms and functions [16], the construction typology, the use of energy-efficient window glazing and frames (windows - glazing and frames, combined - should have U-factors not exceeding $0.80 \mathrm{~W} / \mathrm{m}^{2} \mathrm{~K}$ with solar heat-gain coefficients around 50\%), an application of solar shields as shown in Fig. 8.

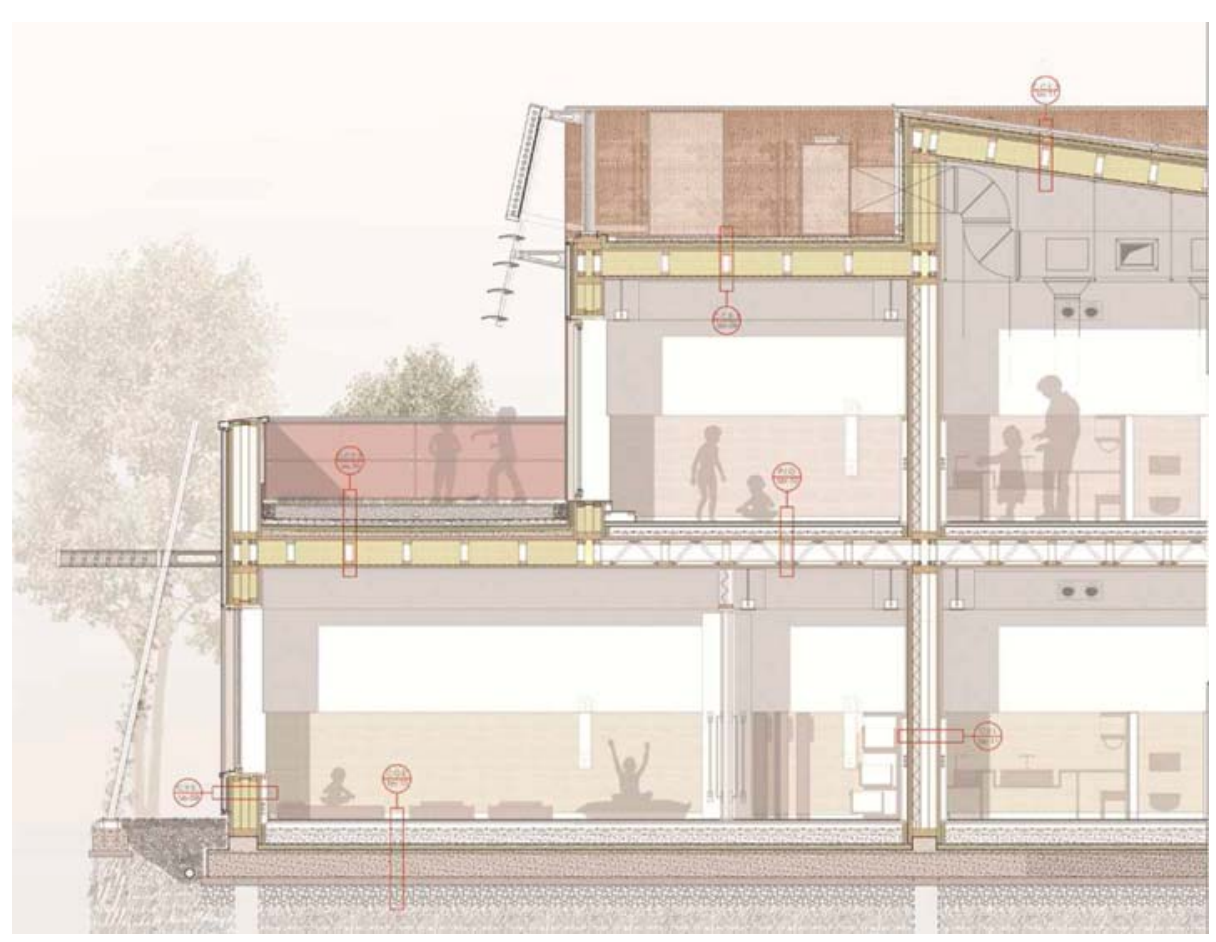

Figure 7: An energy-efficient school project in a Mediterranean context. The section on the southern side is characterized by solar shading systems, a low transmittance envelope, and natural ventilation solutions for night cooling. Final workshop, Eco-efficient Architecture, Faculty of Architecture of Bologna, 2010. 


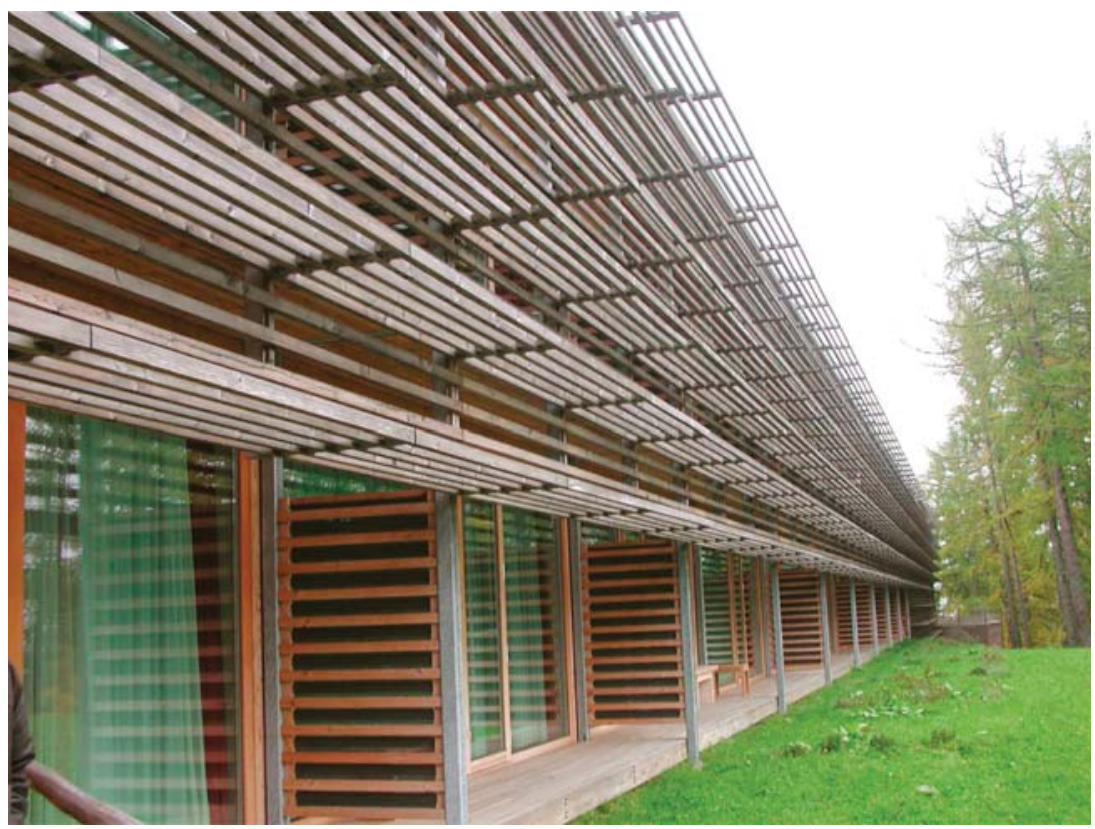

Figure 8: Shaded surface in a bioclimatic hotel. Class A Klimahouse [19]. Vigilius Mountain Hotel, Lana - Bolzano $($ HGT $=2791$; monthly average outside temperature during the winter heating period $\left.4.73^{\circ} \mathrm{C}\right)$, Italy, arch. Matteo Thun.

Natural or mechanical ventilation system are of particular importance - they can play an important role in summer cooling, assisting the air change during the night (most of the perceptible heat in the exhausted air is transferred to the incoming fresh air) - as well as a passive preheating of the fresh air which may be brought into the house through underground ducts that exchange heat with the soil [17].

It is fundamental to work consciously to integrate - into the architectural design strategies energy saving factors to realize buildings characterized by conditions of natural hydrothermal comfort with minimal energy use [18].

\section{AN INTERESTING CASE STUDY: PASSIVE HOUSE IN MONTIANO}

An interesting Italian case study is a passive house recently built in Montiano, a small town on the hills of the Region of Emilia Romagna (as shown in Fig. 9). The architects of Officina 4 Studio, in collaboration with TBZ - Physics Building Center - thought to relate the house to its context, looking for a morphological relation.

In this project, the energy efficiency criteria, based on the passive house standard, are coordinated with respect to the genius loci, the morphology, and the local traditional materials [20]. The house, of a wooden structure, is well integrated in the context and its surrounding landscape and it is characterized by interesting experimental solutions.

The construction of a passive building, with high-efficiency standard, provides for the definition of objectives already in the first phase of design. The site, located on the hills, in a beautiful landscape, led to place the building taking advantage of the correct sun exposure for the summer and winter periods.

The compact form of the building, consisting of a parallelepiped with the integrated volume of stairs, provides a good index of compactness, with few dispersant surfaces. 


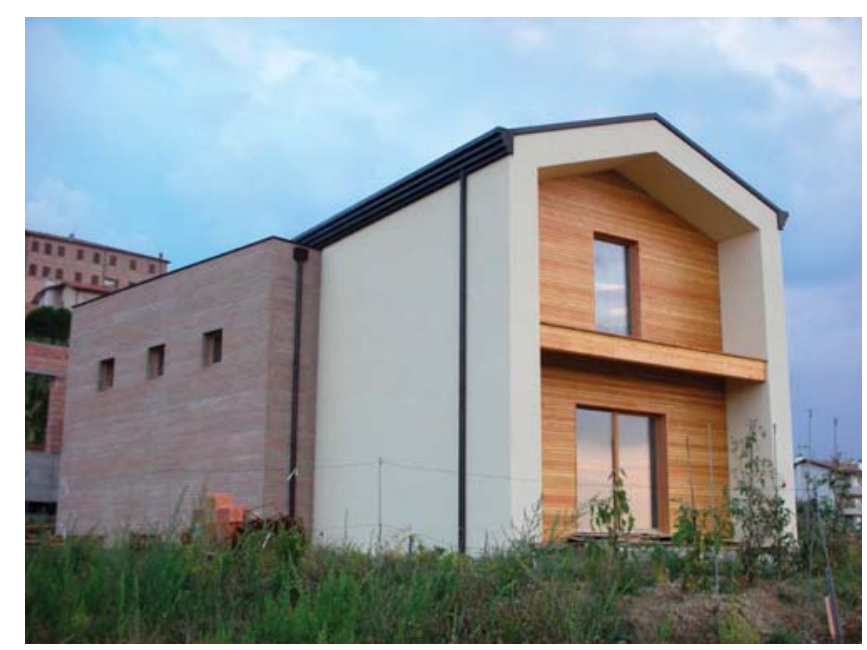

Figure 9: Montiano (FC), Italy, HGT = 2356. Passive residential building. The regular and compact shape helps the energy control; the orientation and limited size of clear surfaces limit summer overheating.
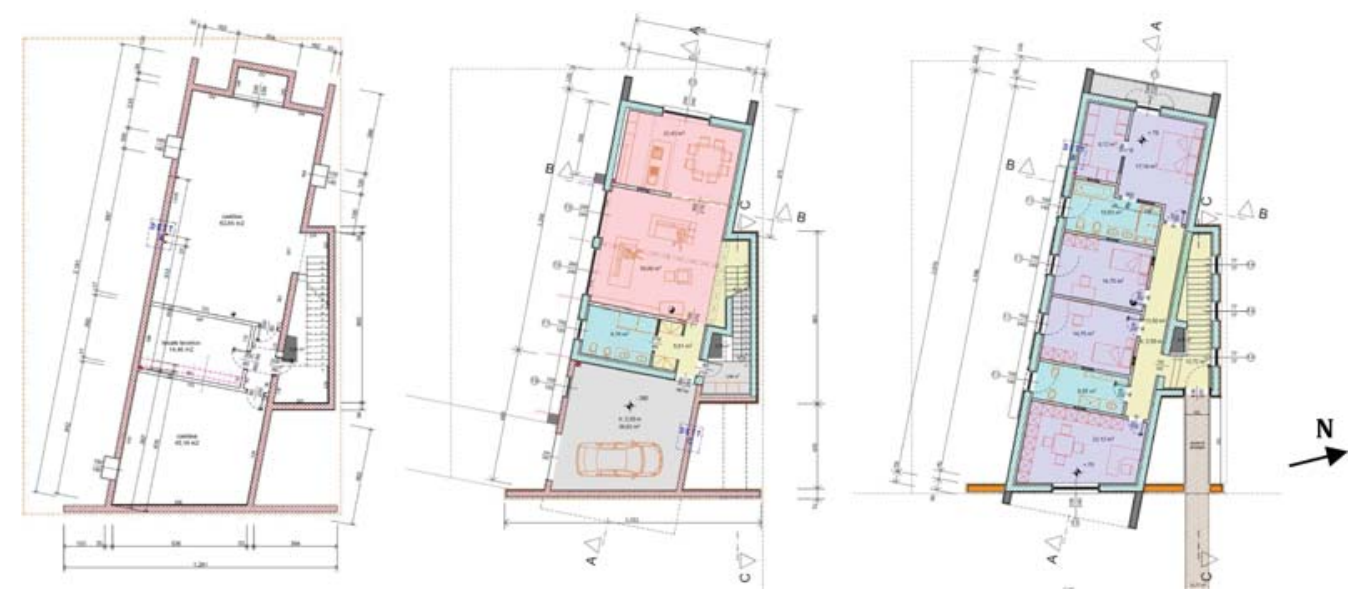

Figure 10: The three floors of the passive house in Montiano. The northern part is closed and features the stairs and the boiler room. The southern part of the building features the main rooms and is characterized by a regular glazed surface.

This composition is characterized by a slight misalignment of the house in relation to the road. So, the house has an oblique facade and a small footbridge as entrance.

The external elements, such as balconies and footbridge, are independent from the structural point of view, so that they don't represent possible thermal bridges. Materials and technologies remind traditional buildings. Bricks are used for the main facades; plaster and timber cladding characterize the other sides.

The wood structure is erected on a reinforced concrete basement. It is completed with a dry prefabricated system and insulated with a thermal coat as outer layer.

The building has three levels, as shown in Fig. 10: a basement with service areas, including the utilities room, a mechanical ventilation system with heat recovery, a ground floor with living areas 
and garages, a first floor with the sleeping areas and a study (200 sq. $\mathrm{m}$ in total). The plan is of rectangular shape, with sides about $7 \mathrm{~m}$ and $20 \mathrm{~m}$, respectively, articulated on two floors. The thermal envelope encloses the residential area including the stairs of the two living levels, excluding the basement, the garage, and the bottom of the stairwell.

With the exception of the basement, realized with reinforced concrete, the rest of the building is entirely built with a dry and light structure (as shown in Fig. 11) of plywood elements. Particular attention was paid to the high quality performances of the envelope, erected with vertical wood Finnjoist TJI double-T profiles and a core of OSB, plus OSB panels and DHF plates, as shown in Fig. 12.

The cavity of each envelope element, $30 \mathrm{~cm}$ thick, was filled with cellulose (density of $60 \mathrm{~kg} / \mathrm{m}^{3}$ ), of particular ecological and high insulating performance. The envelope is completed with a mineralized and plastered wood panel applied on the outside.

This layer contributes to create a continuous skin which can limit the permeability of the facades to the wind. On the inside, there is a small cavity $(7.5 \mathrm{~cm})$ for the electrical equipment covered by a double layer of drywall and insulated with wood wool, as shown in Fig. 13.

The envelope has an extremely low transmission, of $0,11 \mathrm{~W} / \mathrm{m}^{2} \mathrm{~K}$, a value lower than the limit set by the passive house standard $\left(0,15 \mathrm{~W} / \mathrm{m}^{2} \mathrm{~K}\right)$. During summer the phase displacement exceeds 20 hours, an optimal result (in the protocol 'ITACA', inspired by the international GBC - Green Building Challenge - system, the maximum score is assigned for lags greater than 12 hours. This national Protocol is one of the assessment evaluation systems for environmental sustainability of buildings, developed by Italian Regions. It is based on SBMethod developed by iiSBE Italy, together with ITC-CNR and ITACA).

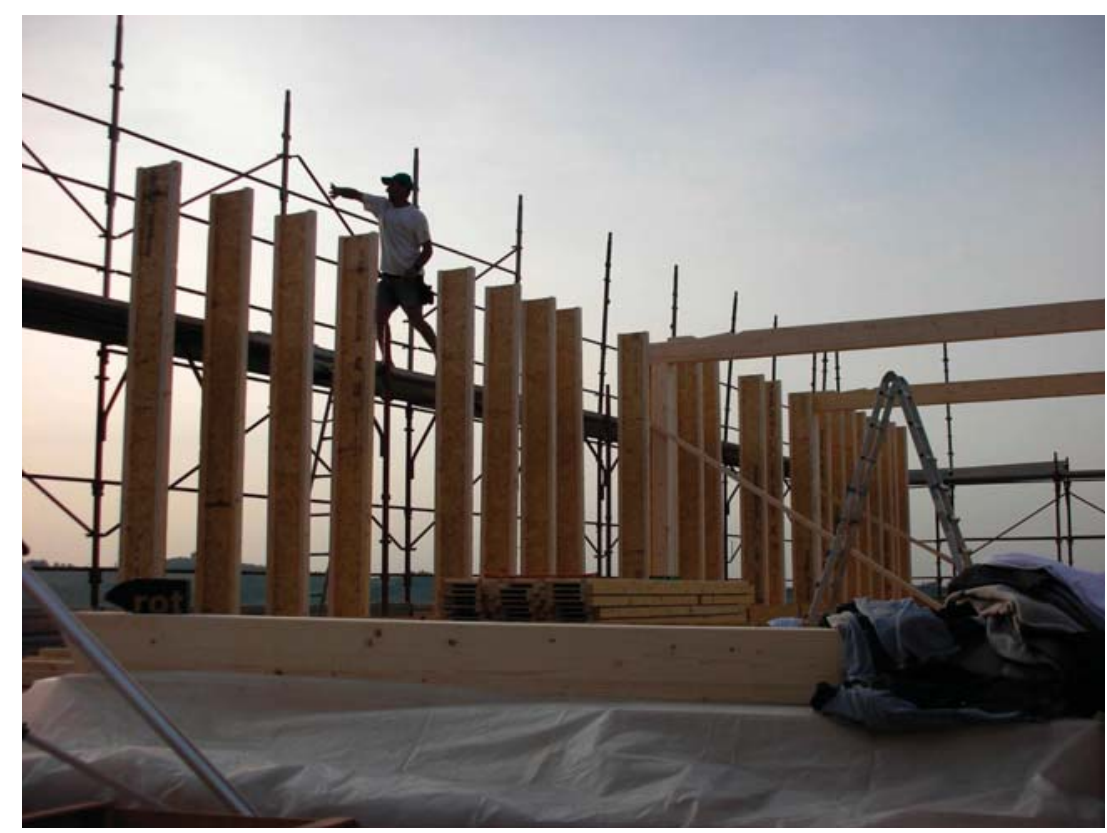

Figure 11: The wooden structure erected on the reinforced concrete basement. The concrete portions were built in three months. The upper wooden structure was built in two weeks. 


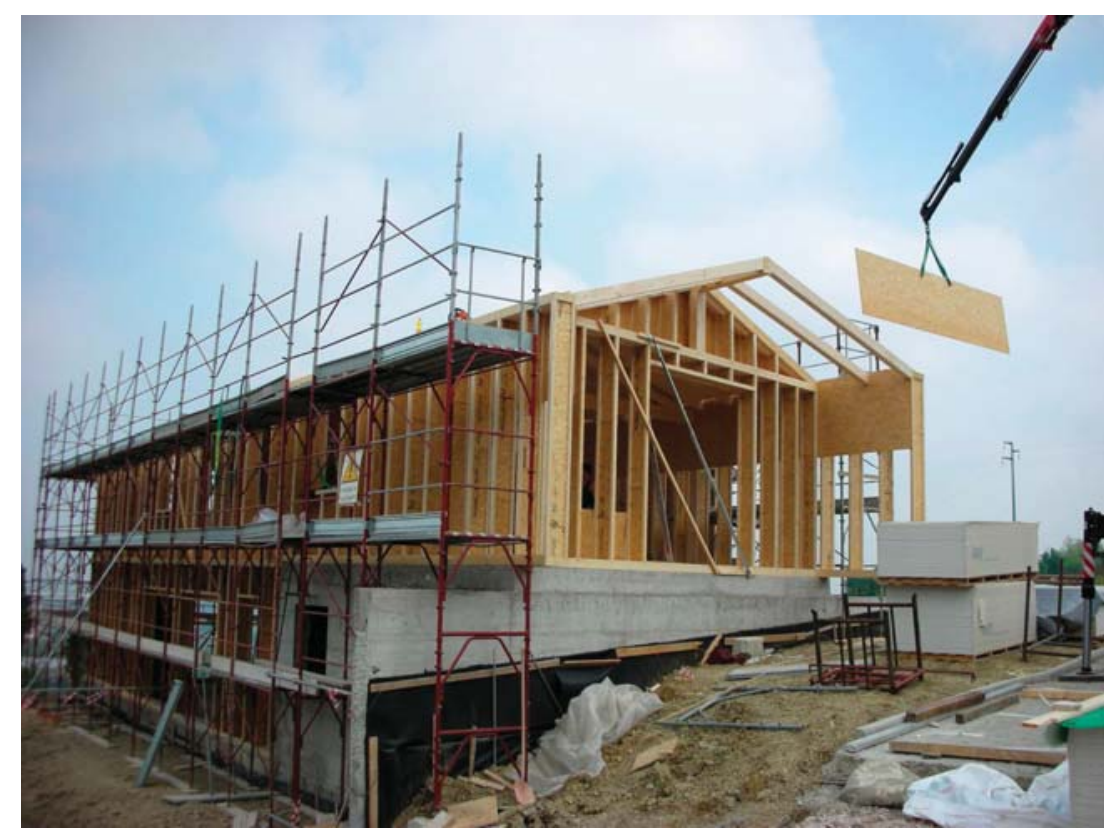

Figure 12: One of the construction phases with application of dry technological system.

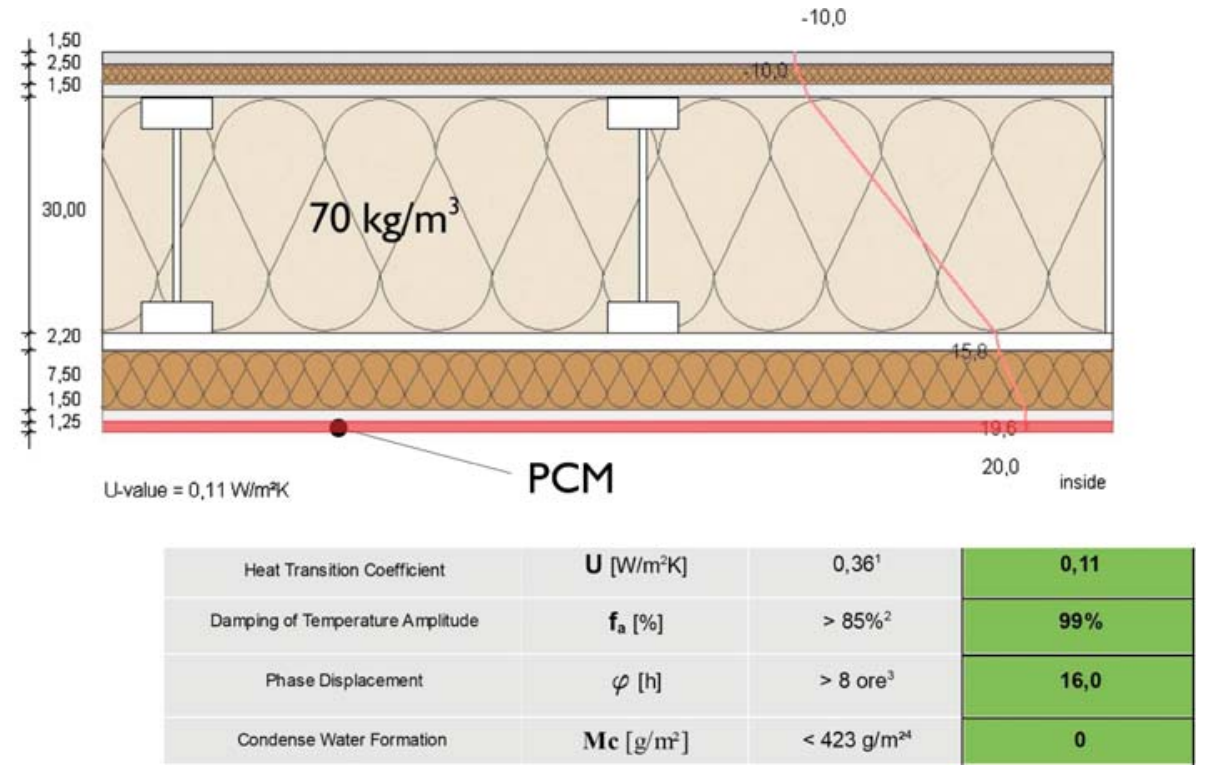

Figure 13: Thermal behavior during winter and summer seasons of the passive house envelope: $\mathrm{U}=0.11 \mathrm{~W} / \mathrm{m}^{2} \mathrm{~K}$, phase displacement $=16$ hours. Layers of the envelope: plasterboard $(1.25 \mathrm{~cm}+1.25 \mathrm{~cm})$, service duct with insulation $(7.50 \mathrm{~cm})$, OSB $(2.00 \mathrm{~cm})$, TJI and insulation in cellulose $(30.00 \mathrm{~cm})$, DHP AGEPAN $(1.50 \mathrm{~cm})$, Eraclit $(2.50 \mathrm{~cm})$, plaster $(1.50 \mathrm{~cm})$. 
Inside, the walls are covered with Micronal PCM (Phase Change Material) BASF panels, latent heat accumulators that contribute to maintain the internal temperature constant through the phase change of materials they are made of. These panels contain microscopic capsules of wax, whose melting point is between $22^{\circ} \mathrm{C}$ and $26^{\circ} \mathrm{C}$, as can be seen in Fig. 14 .

When the inside temperature rises, the PCM turns liquid, that is, the wax melts, storing energy without raising the indoor temperature. To the contrary, when the inside temperature goes down, the PCM is solidified, releasing heat and therefore helping to maintain a constant indoor temperature. The microcapsules, with a polymer shell containing wax, act as latent heat storage: the panels have a thermal capacity of about $330 \mathrm{~kJ} / \mathrm{m}$ with a thickness of just $15 \mathrm{~mm}$.

The building was erected quickly: the parts in cement, in contact with the ground, were completed in three months. The wooden structures were erected in just two weeks. The components arrived on site ready for application and lots of them were pre-assembled, to accelerate the assembly phase. The trusses allow to have no middle support and a free span of more than 6 meters. Finnjoist elements with composite profile were also used for the roof. The $30 \mathrm{~cm}$ thick cavity was filled with cellulose, buffered with panels like those used for the walls.

The roof coating was realized with tiles placed on crossed battens to favor natural ventilation. The frames have passive houses performances, with energy-efficient, triple-glazed and low-emissivity glass.

The controlled mechanical ventilation system (Zehnder), whose power equipment is located in the basement, deserves special attention. In a passive building that aims at providing high energy performance with excellent levels of comfort, the synergy between the aspects of construction and plants is fundamental: the entire system has to provide an integrated performance. A diagnostic tool can be seen in Fig. 15.

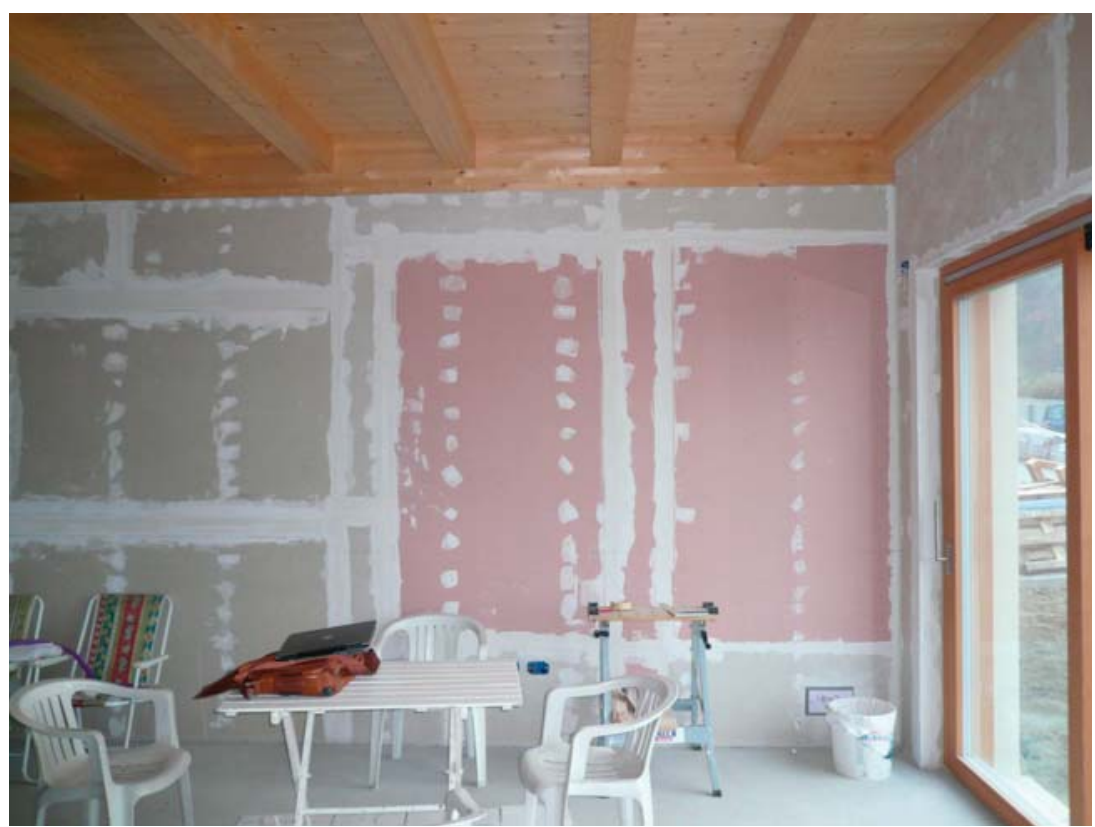

Figure 14: Preparation of radiant wall panels in Micronal PCM (Phase Change Material). The panels contribute to avoid overheating during summer, holding temperature between 22 and $23^{\circ} \mathrm{C}$. 


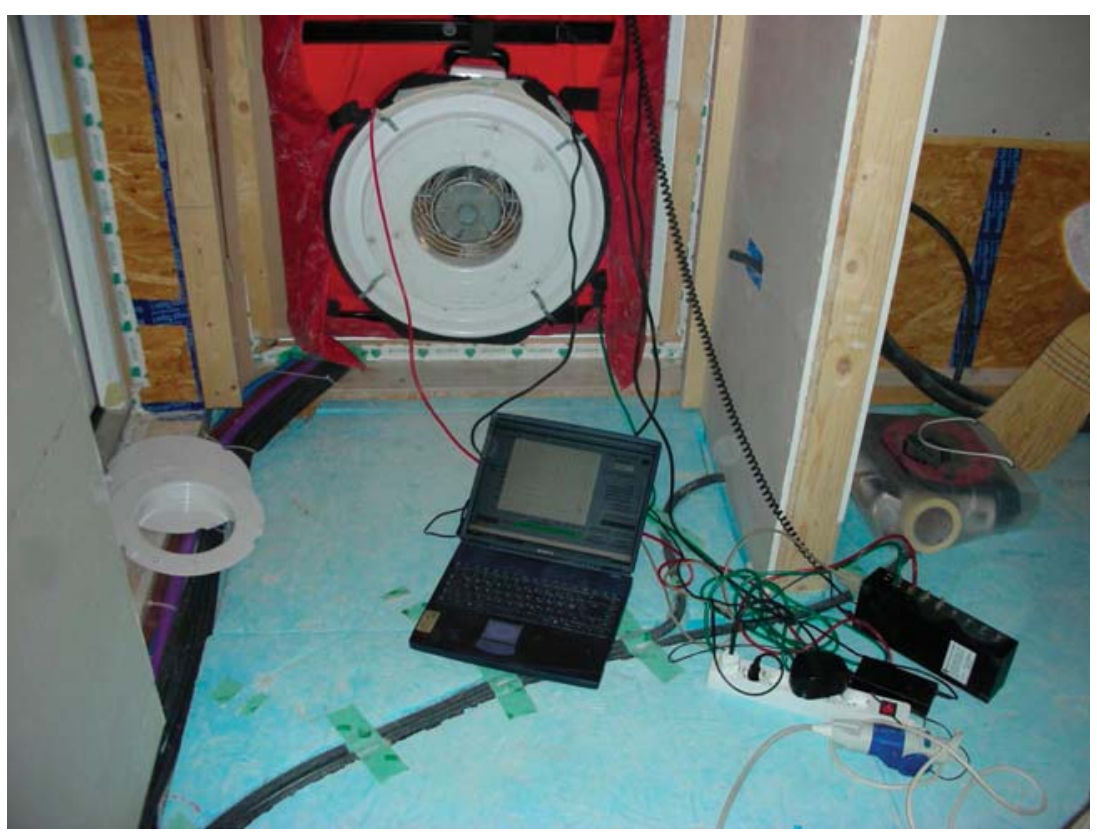

Figure 15: Blower door test. It is a diagnostic tool designed to measure the air-tightness of buildings and to help locate air leakage sites.

The air, coming from outdoor and simply filtered, is fed through underground conduits, exchanging heat with the soil to achieve an effect of pre-cooling during summer and of pre-warming during winter.

So the air goes in, distributing through the living spaces and it is recovered into the service rooms: the two flows interact through a highly efficient heat exchanger that transfers the energy from the incoming to the outgoing airflow. Therefore, the air supply is continuous with minimal heat loss, while ensuring high levels of indoor comfort and energy efficiency, as shown in Fig. 16.

To ensure high levels of heat containment, the envelope is adequately waterproofed. In particular, each connection with the dry system is watertight and air-proof. The outer layer of plaster, applied on wood panels, contributes to smooth the surface discontinuities.

Among the options for the future, possible additional solutions are provided to improve the energy performances of this building. An additional contribution of renewable energy can be ensured by applying a geothermal auger and solar panels.

Although the openings are sized according to the needs of indoor lighting and the clear envelope is limited to reduce the risk of overheating during summer, the architect is considering the adoption of external shading elements applied on the southwest side.

\section{CONCLUSION}

The above case study could represent a key source for an analysis of the methodologies and strategies of intervention to be applied on one of the most widespread building typologies present on our national territory.

It combines standard features with singular peculiarities. The components and systems used in this case aim at maximizing the energy efficiency with simple technologies, at limiting costs within the market average values, and at considering the high level of compatibility with the contexts [21]. 


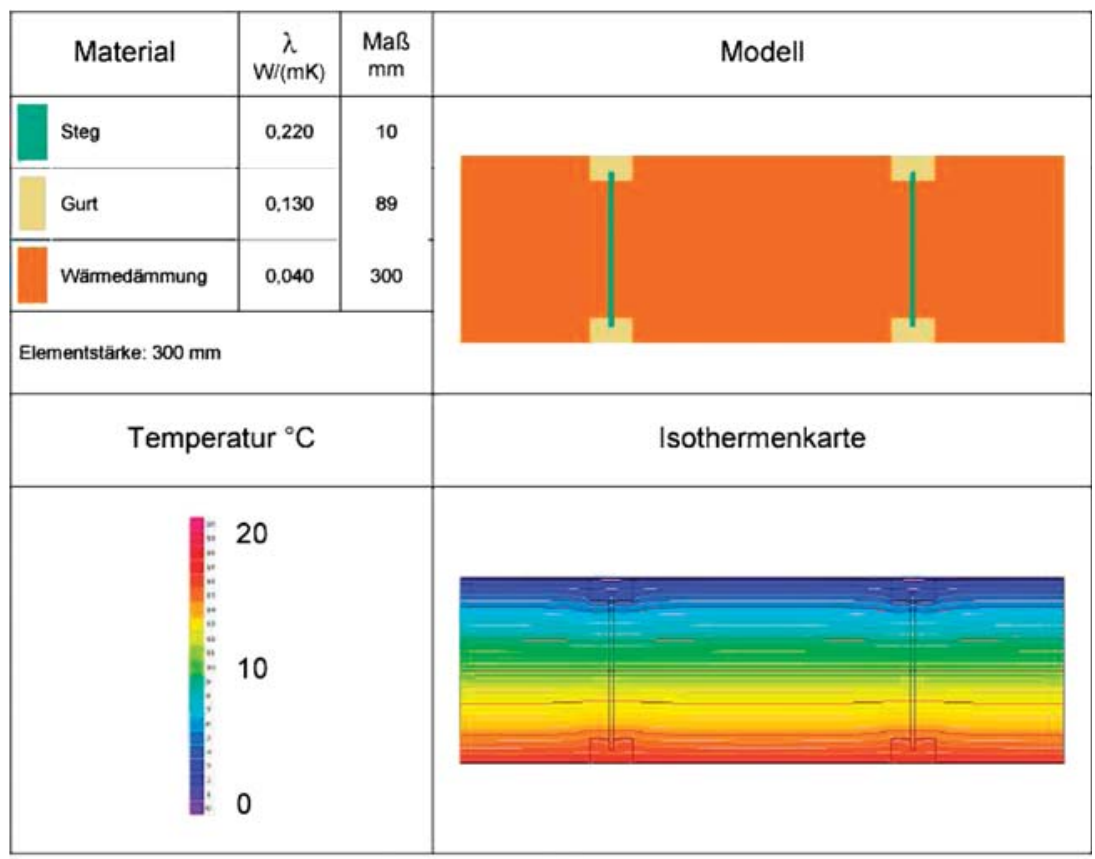

Berechnungsergebnis nach E DIN EN ISO 10211:

\begin{tabular}{|l|c|c|c|}
\hline $\begin{array}{l}\text { Bezugstemperaturdifferenz des } \\
\text { Wärmedurchgangskoeffizienten }\end{array}$ & $\Delta \Theta$ & 30 & $\mathrm{~K}$ \\
\hline linearer Wärmedurchgangskoeffizient & $\Psi_{\mathrm{a}}$ & 0.011 & $\mathrm{~W} /(\mathrm{mK})$ \\
\hline
\end{tabular}

Figures 16: Thermo-graphic diagram of the envelope system realized with Finnjois.

The strategies applied in this building are representative of a design approach for the Mediterranean area.

Especially during summer, and in addition to the transmittance, it is important to assess the contribution of the mass materials in relation to the higher heat capacity to reduce the effects of external thermal variations on the indoor microclimate. The role of heat inertia, although extremely important in the characterization of energy efficiency of buildings during summer, cannot leave aside a more general design strategy aimed at a correct relationship with the environment. Among the main parameters, the most important ones are the location, the shape, and orientation of the building: a southern orientation and shade considerations are some of the basic features that distinguish passive house construction [22].

The ratio of dispersing surfaces and volume is an index of energy efficiency and it is considered a reference for regulations.

Other features of a passive house consist of a suitable distribution of rooms and functions, the construction typology, the use of energy-efficient window glazing and frames (windows - glazing and frames, combined - should have U-factors not exceeding $0.80 \mathrm{~W} / \mathrm{m}^{2} \mathrm{~K}$ with solar heat-gain coefficients around 50\%), and an application of solar shields. Natural or mechanical ventilation systems are of particular importance - they play an important role in summer cooling, encouraging the air change during the night (most of the perceptible heat in the exhausted air is transferred to the 
incoming fresh air) - as well as a passive preheating of fresh air which may be brought into the house through underground ducts allowing to exchange heat with the soil.

For buildings characterized by conditions of natural hydrothermal comfort, it is fundamental to integrate all energy-saving factors, therefore minimizing the use of energy.

\section{REFERENCES}

[1] Energy Efficienty in Buildings - European Commission, EUROPE 2020 initiative - Energy Efficiency Plan 2011. Available at: http://ec.europa.eu/energy/efficiency/action_plan/action_ plan_en.htm

[2] Wienke Uwe, L'edificio Passivo - Standard, Requisiti, Esempi, Alinea: Firenze, 2002.

[3] Passive House Institute, Available at http://www.passiv.de/

[4] Cost Efficient Passive Houses as European Standards - THERMIE Programme of the European Commission, Available at http://www.cepheus.de/eng/index.html

[5] VV. AA., 11th International Conference on Passive Houses - Proceedings, Bregenz 2007, Passivhaus Institut: Darmstadt, 2007.

[6] Efficiency Research Group, Passive on Project, Rockwoll: Milano.

[7] The Passive-On Project - Intelligent Energy for Europe SAVE programme, Available at http:// www.passive-on.org/en/

[8] VV. AA., Costruire sostenibile: il Mediterraneo (Cuore Mostra SAIE), Alinea: Firenze, 2001.

[9] Carotti, A., La Casa Passiva in Europa, Clup: Milano, 2005.

[10] Carotti, A. \& Madè, D., La Casa Passiva in Italia, Rockwoll: Milano, 2006.

[11] Boeri, A. \& Longo, D., Strategies for the promotion of energy efficient design in Italian historical contexts, in INTED 2009 - Proceedings of International Technology, Education and Development Conference: Valencia, 2009.

[12] Barozzi, A. \& Ghini, A., The passive house in a temperate climate. Energy balance building envelope system, in VV. AA., Bologna-Delft First Meeting for Knowledge Exchange, DAPT University of Bologna - Delft University of Technology: Bologna, 2005.

[13] Colombo, G., Edifici Passivi, Alinea: Firenze, 2006.

[14] Boeri, A., Riqualificazione energetica, in Progettazione ed efficienza energetica, Rinaldi, A., Maggioli: Rimini, pp. 184-203, 2010.

[15] VV. AA., +Qualità-Energia. Per costruire sostenibile, Be-ma: Milano, 2008.

[16] Novi, F., La riqualificazione sostenibile, Alinea: Firenze, 1999.

[17] Sassi P., Strategies for Sustainable Architecture, Taylor \& Francis: New York, 2006.

[18] Boeri, A., Criteri di progettazione ambientale, Delfino: Milano, 2007.

[19] Klima Haus Agentur, Available at http://www.agenziacasaclima.it/

[20] Barucco, M.A. \& Trabucco, D., Architettura_Energia, Edicom: Montefalcone: Gorizia, 2007.

[21] Hendriks, Ch. F., Sustainable construction, Aeneas technical publishers: The Netherlands, 2001.

[22] Smith, P., Eco-Refurbishment, Architectural Press: Oxford, 2004. 